\title{
Pure torsional nystagmus as a consequence of head trauma
}

\author{
T. D. SABIN AND J.A. POCHE \\ From the USPHS Hospital, Carville, Louisiana, and Louisiana State \\ University School of Medicine, U.S.A.
}

Conjugate torsional eye movements cannot be produced by volition, but do occur reflexly in a manner serving to retain visual fixation when the head is tilted (Cogan, 1956). In experimental animals conjugate torsional movements occur with stimulation of the zona incerta or the interstitial nucleus of Cajal (Hyde and Toczek, 1962).

Spontaneous conjugate torsional eye movements in man appear clinically as a component movement in rotary nystagmus and see-saw nystagmus. The purpose of this paper is to present a case in which nystagmus was composed of purely torsional movements (Fig. 1C).

\section{CASE REPORT}

J. C. (case 2867), a 70-year-old white male, was well until 2 September 1921. In the course of his employment a heavy metallic valve struck him on the forehead, immediately rendering him unconscious for approximately 13 hours. He bled from his nose and left ear. Upon awakening he had a severe visual impairment, perceiving only bright light held immediately in front of him. His vision began to improve in three days and he complained of diplopia in all directions of gaze and inability to see objects in the lateral field of each eye. His vision continued to improve, and six months after the trauma he was able to recognize persons and objects, and eventually to read printed material. During this period he noted oscillopsia and horizontal head nodding with attempted fixation. Another immediate consequence of the head trauma was a definite diminution of auditory acuity on the left. $\mathrm{He}$ denied other CNS sequelae. He returned to light work three months after the injury.

He was admitted to this hospital in May 1968 with a diagnosis of lepromatous leprosy.

PHYSICAL EXAMINATION Height 5ft. $8 \frac{1}{2}$ in. $(1 \cdot 7 \mathrm{~m})$, weight $171 \mathrm{lb}$. $(77.5 \mathrm{~kg})$ temperature $98.2^{\circ} \mathrm{F}\left(36.8^{\circ} \mathrm{C}\right)$, pulse $80 / \mathrm{min}$, respiration $18 / \mathrm{min}$, blood pressure $130 / 82$ $\mathrm{mm} \mathrm{Hg}$.

${ }^{1}$ This work was supported by Social and Rehabilitation Service Grant No. RC-40-M.
GENERAL EXAMINATION His skin was generally thickened and there was a diffuse confluent macular rash occurring over both arms, and several large raised lesions over the trunk. There was lateral thinning of the eyebrows and enlargement of the ear-lobes. The remainder of the general examination was unremarkable.

NEUROLOGICAL EXAMINATION He was oriented in all spheres and had an adequate fund of general knowledge.

CRANIAL NERVES Olfaction was preserved bilaterally. The fundi showed moderate arteriolar narrowing. The discs appeared normal. Corrected visual acuity was 20/20 in the right eye and 20/300 in the left eye. A bitemporal hemianopia was present with right macular sparing but involving left central vision (Fig. 2). Examination of the eye movements revealed a spontaneous torsional movement bilaterally. The alternating clockwise-counterclockwise torsional movements occurred about an imaginary axis from the centre of the pupil through the fovea. This axis however was stationary (Fig. 1C). Extorsion in one eye was accompanied by intorsion of the other and the arc and rate of torsion were the same in both eyes. This nystagmus was present in the primary position of gaze, uninhibited by fixation, and ceased on attempted conjugate gaze to either side or downward. On conjugate upward gaze the torsional movements became quicker and the arc of deviation smaller. Movements were approximately 100/min on direct gaze and 175/min on upward gaze. There was an exotropia of the left eye but it showed a full range of movement when the right eye was covered. Opticokinetic nystagmus was intact. Audiograms revealed a moderately severe hearing loss greater on the left side (Fig. 3). Other cranial nerves were within normal limits.

MOTOR SYSTEM There was marked wasting and weakness of all intrinsic hand muscles bilaterally. Bilateral foot-drop and also complete paralysis of intrinsic musculature of feet were present. Deep tendon reflexes were active and equal bilaterally. No pathological reflexes were elicited. The gait was steppage. Cerebellar function was normal.

SENSORY EXAMINATION There was an extensive, symmetrical, dense cutaneous sensory loss that showed sparing of the relatively warmer body areas (Sabin, 1969). 


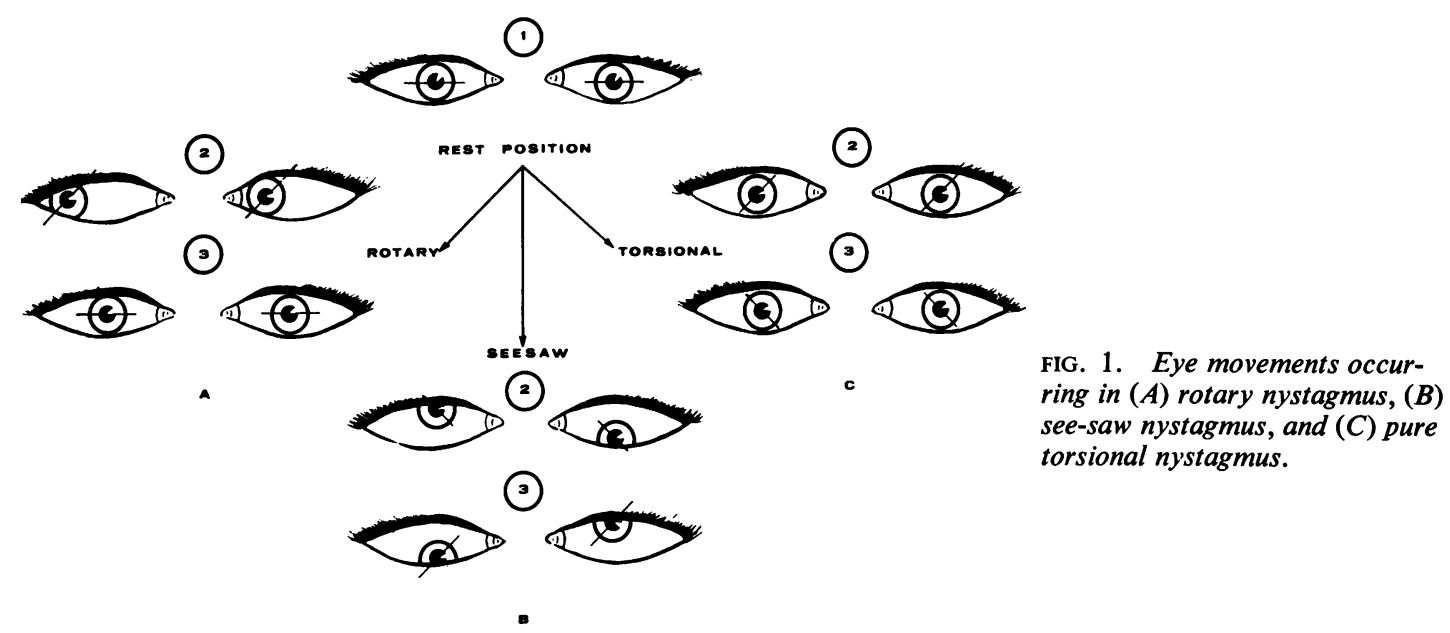

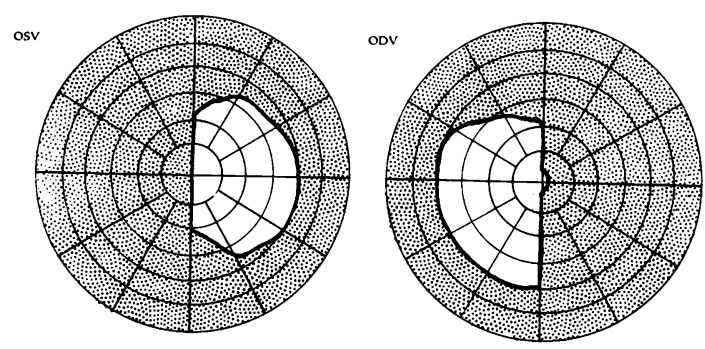

FIG. 2. Tangent screen examination with a $3 \mathrm{~mm}$ object at $1 \mathrm{~m}$.

LABORATORY TESTS Results of these were as follows: haematocrit $41 \%$, Hb $14.6 \mathrm{~g} \%$, WBC $8,450 / \mathrm{mm}^{3}$, BUN $20 \mathrm{mg} \%$, FBS $88 \mathrm{mg} \%$, PBI $9.6 \mathrm{~g} \%$. Serum thyroxine level was normal. VDRL was non-reactive. Spinal fluid was clear and colourless. Sugar was $65 \mathrm{mg} \%$ and chlorides $118 \mathrm{~m}$-equiv/1. The protein was $34 \mathrm{mg} \%$ and there were no cells present. Colloidal gold was 000000000 . Skull radiographs revealed no abnormalities. Caloric testing was carried out according to the method of Fitzgerald and Hallpike (1942) and demonstrated no definite abnormality (Fig. 4).

\section{DISCUSSION}

The extensive cutaneous sensory loss and multiple peripheral nerve deficits the patient demonstrated were typical of lepromatous leprosy.

Torsional eye movements have been considered to be under the control of the utricle because of their occurrence with tilting of the head (Kompanejetz, 1928). The torsional movements occurring in rotary nystagmus are accompanied by a movement of the optic axis and both movements have a fast and slow component (Fig. 1A). Because no fast components were observed in the torsional movements of the present case and the occurrence of bitemporal hemianopia, the torsional nystagmus in the present case more closely resembles that seen in see-saw nystagmus. This syndrome was described by E. ET Maddox in 1914 and consists of alternating verticaP eye movements accompanied by intorsion of the rising eye and extorsion of the falling eye (Fig. 1B) Drachman (1966) reviewed 13 cases in the literature and added two of his own. He underscored the frequency of visual deficits (11 of 13 so examined hae bitemperal hemianopia) and decreased acuity.

See-saw nystagmus has been attributed to ocula음 or visual abnormalities (Lourie, 1963), brain-stem lesions (Jensen, 1959; Daroff, 1965), and diencephalic lesions (Kinder and Howard, 1963). Drachman (1966) considered that the syndrome of see-saw nystagmus probably represented a combined disorder, since experimental evidence failed to indicate that any one brain area controlled both vertical and torsional eye movements. If combined lesions produce see-saw nystagmus, then discrete lesions might produce either the vertical or the torsional component of the nystagmus in the absence of the other. The present case would then represent this phenomenon. This case is also unusual in that the torsional nystagmus linked directly to trauma. Traquair, Dott, and Russell (1935) reported 30 cases of traumatic lesions of the optic chiasm. Six of these cases showed unilateral impairment of the auditory nerve, uniformly preceded by a history of bleeding from that ear. None of these cases demonstrated nystagmus. This case indicates that torsional movements of the type seen in see-saw nystagmus occur without the vertical component and that a different anatomical-physiological mechanism may be concerned in the two components of the syndrome. 


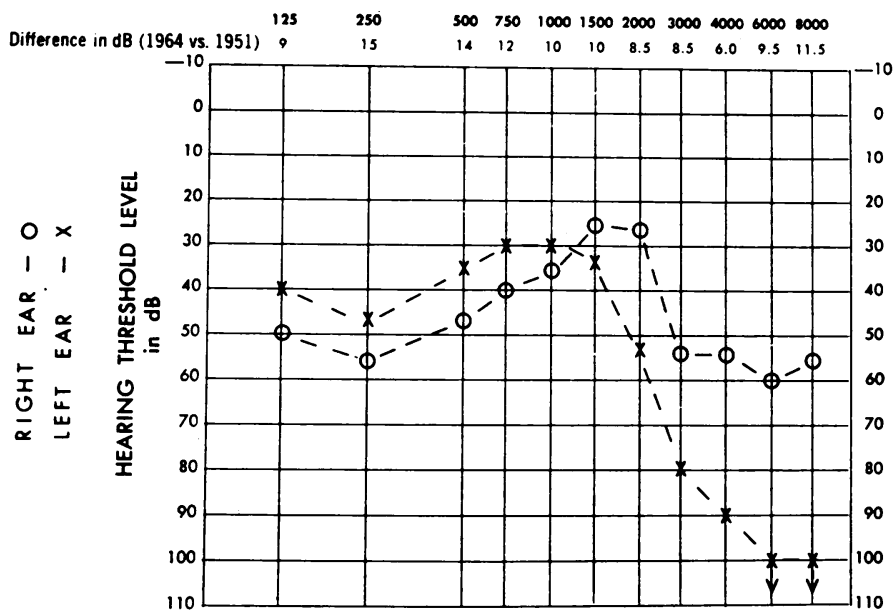

FIG. 3. Audiogram revealed a moderately severe hearing loss, greater on the left.
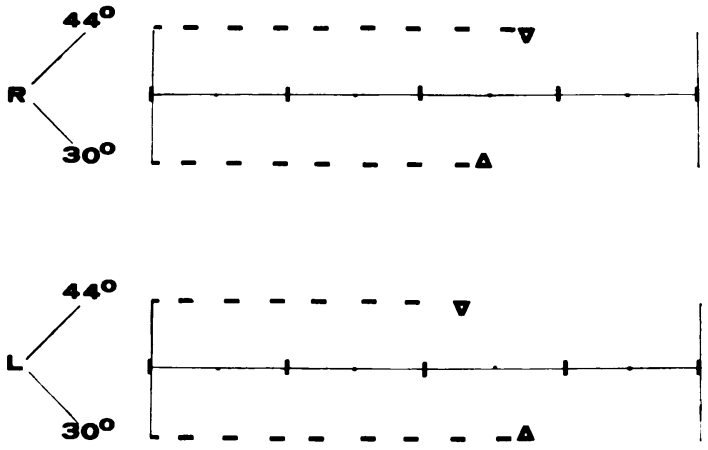

FIG. 4. Caloric testing showed the sum of the duration of the nystagmus to the right was 40 seconds greater than for nystagmus to the left.

\section{SUMMARY}

A case of torsional nystagmus is presented in which eighth nerve abnormalities occurred together with decreased visual acuity and bitemporal hemianopia. The occurrence of bitemporal hemianopia, decreased visual acuity, and abnormal eye movements of this type closely approximate the syndrome of see-saw nystagmus. This case represents a separation of the two movements of see-saw nystagmus perhaps on the basis of a more discrete lesion. The onset of these deficits with a traumatic event is unusual.

\section{REFERENCES}

Cogan, D. G. (1956). Neurology of the Ocular Muscles, 2nd ed., p. 127. Thomas: Springfield, Illinois.

Daroff, R. B. (1965). See-saw nystagmus. Neurology (Minneap.), 15, 874-877.

Drachman, D. A. (1966). See-saw nystagmus. J. Neurol. Neurosurg. Psychiat., 29, 356-361.

Fitzgerald, G., and Hallpike, C. S. (1942). Studies in human vestibular function. 1. Observations on the directional preponderence ('Nystagmusbereit Schaff') of caloric nystagmus resulting from cerebral lesions. Brain, 65, 115-137.

Hyde, J. E., and Toczek, S. (1962). Functional relation of interstitial nucleus to rotatory movements evoked from zona incerta stimulation. J. Neurophysiol., 25, 455-466.

Jensen, O. A. (1959). See-saw nystagmus. Brit. J. Ophthal., 43, 225-229.

Kinder, R. S. L., and Howard, G. M. (1963). See-saw nystagmus. An unusual sign of lesions near the third ventricle. Amer. J. Dis. Child., 106, 331-332.

Kompanejetz, S. (1928). Investigation on the counterrolling of the eyes in optimum head-positions. Acta Oto-Laryng. (Stockh.), $12,332-350$

Lourie, H. (1963). See-saw nystagmus. Case report elucidating the mechanism. Arch. Neurol. (Chic.), 9, 531-533.

Maddox, E. E. (1914). See-saw nystagmus with bitemporal hemianopia. Proc. roy. Soc. Med. (Sect. Neurol. Ophthal. Otol.), 7, xii-xiii.

Sabin, T. D. (1969). Temperature-linked sensory loss. Arch. Neurol. (Chic.), 9, 257-262.

Traquair, H. M., Dott, N. M., and Russell, W. R. (1935). Traumatic lesions of the optic chiasma. Brain, 58, 398-411. 